\title{
Autophagy-related signaling pathways are involved in cancer (Review)
}

\author{
${\text { CAIXIA } \mathrm{CHEN}^{1 *}, \mathrm{HUI} \mathrm{GAO}^{2 *} \text { and XIULAN SU }}^{1}$ \\ ${ }^{1}$ Clinical Medicine Research Center, The Affiliated Hospital, Inner Mongolia Medical University, \\ Hohhot, Inner Mongolia 010050; ${ }^{2}$ Department of Thoracic Surgery, Inner Mongolia \\ Autonomous Region Cancer Hospital, Hohhot, Inner Mongolia 010020, P.R. China
}

Received March 11, 2020; Accepted October 20, 2020

DOI: $10.3892 /$ etm.2021.10142

\begin{abstract}
Autophagy is a self-digestion process in cells that can maintain energy homeostasis under normal circumstances. However, misfolded proteins, damaged mitochondria and other unwanted components in cells can be decomposed and reused via autophagy in some specific cases (including hypoxic stress, low energy states or nutrient deprivation). Therefore, autophagy serves a positive role in cell survival and growth. However, excessive autophagy may lead to apoptosis. Furthermore, abnormal autophagy may lead to carcinogenesis and promote tumorigenesis in normal cells. In tumor cells, autophagy may provide the energy required for excessive proliferation, promote the growth of cancer cells, and evade apoptosis caused by certain treatments, including radiotherapy and chemotherapy, resulting in increased treatment resistance and drug resistance. On the other hand, autophagy leads to an insufficient nutrient supply in cancer cells and the destruction of energy homeostasis, thereby inducing cancer cell apoptosis. Therefore, understanding the mechanism of the double-edged sword of autophagy is crucial for the treatment of cancer. The present review summarizes the signaling pathways and key factors involved in autophagy and cancer to provide possible strategies for treating tumors.
\end{abstract}

\section{Contents}

1. Introduction

2. Initiation and classification of autophagy

3. Signaling pathways in autophagy and tumors

Correspondence to: Professor Xiulan Su, Clinical Medicine Research Center, The Affiliated Hospital, Inner Mongolia Medical University, 1 Tongdao North Street, Hohhot, Inner Mongolia 010050, P.R. China

E-mail:xlsu@hotmail.com

*Contributed equally

Key words: autophagy, cancer, signal pathway, key factors
4. Autophagy-associated antineoplastic agents

5. Conclusions

\section{Introduction}

In the 1960s, researchers first observed that cells degraded intracellular components by wrapping them in a membrane to form a cystic structure and transporting the contents to a small compartment (called the lysosomes) for recycling (1). Due to the difficulties in studying this phenomenon, little was known about it until the early 1990s, when the Japanese molecular cell biologist Ryoshi Ohsumi performed a series of experiments. In the experiments, baker's yeast was used to identify key autophagy genes. The mechanism behind yeast autophagy was further explained and it was demonstrated that human cells use a similar mechanism, a tightly regulated cellular process in which damaged proteins or organelles are wrapped in autophagic vesicles with a bilayer membrane structure, which are transported to lysosomes (mammals) or vacuoles (yeast and plants) for degradation and recycling $(2,3)$. By contrast, autophagy occurs under normal conditions in response to adverse stresses, including hypoxia and nutritional deficiency to supply nutrients and energy and maintain cellular homeostasis. Autophagy can also act as a collective scavenger to degrade unwanted substances (including damaged organelles and misfolded proteins). However, when excessive, autophagy can also lead to autophagic programmed cell death, which leads to the occurrence of several diseases (including neurodegenerative diseases, pathogenic microbial infections and cancer) (4-6). Cancer is a disease with serious metabolic disorders, and autophagy serves dual roles in promoting and inhibiting the occurrence and development of cancer. In addition, numerous signaling pathways and factors are involved in cancer-related processes (7). Beclin1 is a major factor in autophagy, but its expression is downregulated or absent in human ovarian cancer and non-small cell lung cancer, suggesting that Beclin1 is a tumor suppressor $(8,9)$. Notably, Beclin1 is upregulated in colon cancer (10). In addition, numerous tumor suppressor factors (P53, PTEN, AMPK and LKB1) may negatively regulate the mTOR pathway and activate autophagy (11-14). By contrast, oncogenes, including Akt and ERK, can activate the mTOR signaling pathway to 
inhibit autophagy $(15,16)$. Therefore, these factors or their pathways are bridges between autophagy and cancer. However, it is unclear whether tumor suppressors promote or inhibit autophagy. It is necessary to determine the advantages and disadvantages of autophagy is cancer, as well as the roles served by autophagy-associated factors and pathways in cancer in order to improve cancer diagnosis, treatment and prognosis assessment. By reviewing the signaling pathways and factors related to autophagy and cancer, the present review aimed to further clarify the association between autophagy and cancer and its mechanism to provide strategies for the prevention and treatment of cancer.

\section{Initiation and classification of autophagy}

Autophagy is derived from the Greek prefix Auto and is an intracellular catabolic process. At present, it has been demonstrated that there are three types of autophagy, microautophagy, chaperone-mediated autophagy (CMA) and macroautophagy (MAC) (17). Microautophagy is generally an invagination of lysosomal and nuclear membranes, which directly engulf cytoplasmic contents (Fig. 1). CMA selectively degrades proteins containing soluble KFERQ-like motifs. These motifs are recognized by $70-\mathrm{kD}$ heat shock protein (Hsc70) and form complexes with Hsc70 and chaperones proteins; these complexes are then delivered to lysosomes through interactions with lysosome-associated membrane protein (LAMP2A) receptors, resulting in degradation (Fig. 1). MAC, commonly known as autophagy (hereafter referred to as autophagy), occurs through a free bilayer membrane structure derived from the rough endoplasmic reticulum that wraps unwanted organelles/proteins or cytosol to form a structure called an autophagosome, which recognizes and isolates cellular contents that have been labeled by autophagy receptors. Autophagic lysosomes are then fused with lysosomes (mammals) or vacuoles (fungi or plants). During this process, those engulfed organelles/proteins or other components are degraded into amino acids or other raw materials for cell survival or the maintenance of cell nutrition, thereby allowing cells to maintain normal functions under various adverse conditions (2,3) (Fig. 1).

Autophagy includes five stages: autophagy induction, nucleation, autophagosome extension, autophagosome maturation and autophagosome lysis (Fig. 2) (18).

Induction stage: The ULK1-Atg13-FIP200-Atg101 complex is involved in the induction of autophagy (19). Under conditions of sufficient nutrition, mammalian rapamycin target protein complex 1 has a certain activity and can phosphorylate unc-51 like kinase 1 (ULK1) and Atg13 to prevent ULK1 binding to Atg13, FIP200 (FAK-family interacting protein $200 \mathrm{kDa}$ ) and Atg101, thereby inhibiting autophagy. During nutritional deficiency, the activity of mTORC1 on the surface of the lysosome is inhibited, and ULK1 and Atg13 are dephosphorylated, which leads to the activation of ULK1 kinase, and the ULK complex localizes to phagosomes to form the ULK1Atg13-FIP200-Atg101 complex, which induces autophagy. When mTORC1 activity is inhibited, Atg13-Atg1-Atg17 forms and initiates autophagy.

Nucleation stage: The Beclin1 (Atg6)-Atg14LVPS15-VPS34 (PI3K) complex mediates the formation of pre-autophagosomes (PASs) and the initiation of autophagy, and may also recruit associated autophagy proteins (including Atg12-Atg5, Atg6 and LC3). Atg6 and LC3 may promote the expansion and extension of phagosomes (20).

Autophagosome extension: This step is mainly mediated by two ubiquitin-like systems, the Atg5-Atg12 system and the LC3 system (21). Atg7 acts as an E1-like ubiquitin-activating enzyme to activate Atg12; the E2 ubiquitin-transferase Atg10 transfers Atg12 to Atg5 to form an Atg12-Atg5 complex, which then binds with Atg16L to form an E3-like ligase-like Atg12-Atg5-Atg16L complex, which is located on the outer membrane of autophagosomes and participates in membrane expansion (22). At the same time, Atg4 can cleave the C-terminal glycine of proAtg8 (pro-LC3) to form cytoplasmic LC3-I and covalently bind to phosphatidylethanolamine (PE) in response to Atg7 and Atg3 to form an Atg8-PE (LC3-II) fat-soluble complex (22). In addition, the Atg12-Atg5-Atg16L complex can activate the Atg3 enzyme, promote the transfer of Atg8 (LC3) from Atg3 to PE, and promote the formation of the Atg8-PE (LC3-II) complex. These two systems complement each other to promote the expansion and extension of the autophagic membrane (23).

Autophagosome maturation: Soluble N-ethylmaleimidesensitive factor attachment protein receptor (SNARE) serves an important role in cell material transport and specific membrane fusion (24). The PI3K complex (Vps34-Vps15Beclin1) binds to the anti-ultraviolet gene (ultraviolet radiation resistance-associated gene, UVRAG) to form a Vps34-Vps15Beclin1-UVRAG complex (class III phosphatidylinositol kinase complex, PI3KC3), which participates in autophagic maturation and transport. Cheng et al (25) reported that Pacer (protein associated with UVRAG as an autophagy enhancer) is a vertebrate-specific autophagy regulatory molecule. Pacer may directly interact with UVRAG, one of the mammalian PIK3C3 subunits, thereby alleviating Rubicon (complex subunit, autophagy negative regulatory factor)-mediated inhibition of Vps34 kinase. By contrast, Pacer may recruit PI3KC3 and HOPS complex subunits to autophagic vesicles and promote the fusion of autophagosomes and lysosomes. In addition, autophagic lysosome fusion requires the participation of lysosome-associated membrane protein 1 (LAMP1) and lysosome-associated membrane protein 2 (LAMP2) (26).

Autophagolysis: Acid hydrolase in autophagic lysosomes degrades the contents of the vesicles.

\section{Signaling pathways in autophagy and tumors}

Basal autophagy serves an important role in cellular homeostasis by eliminating old or damaged organelles and aggregated intracellular proteins. In the cancer microenvironment, when cancer cells are subjected to stress (glucose/cytokine deficiency, hypoxia, oxidative stress, radiation or anticancer drug therapy), the level of autophagy increases, which leads to the enhancement of cancer cell adaptability (cytoprotective response) and contributes toward the development, proliferation and migration of cancer cells (27). In addition, it has been reported that the level of autophagy was decreased in a variety of cancer types, indicating that autophagy also has a certain anticancer effect (28). Therefore, autophagy serves dual roles in the promotion and inhibition of cancer. The occurrence and 


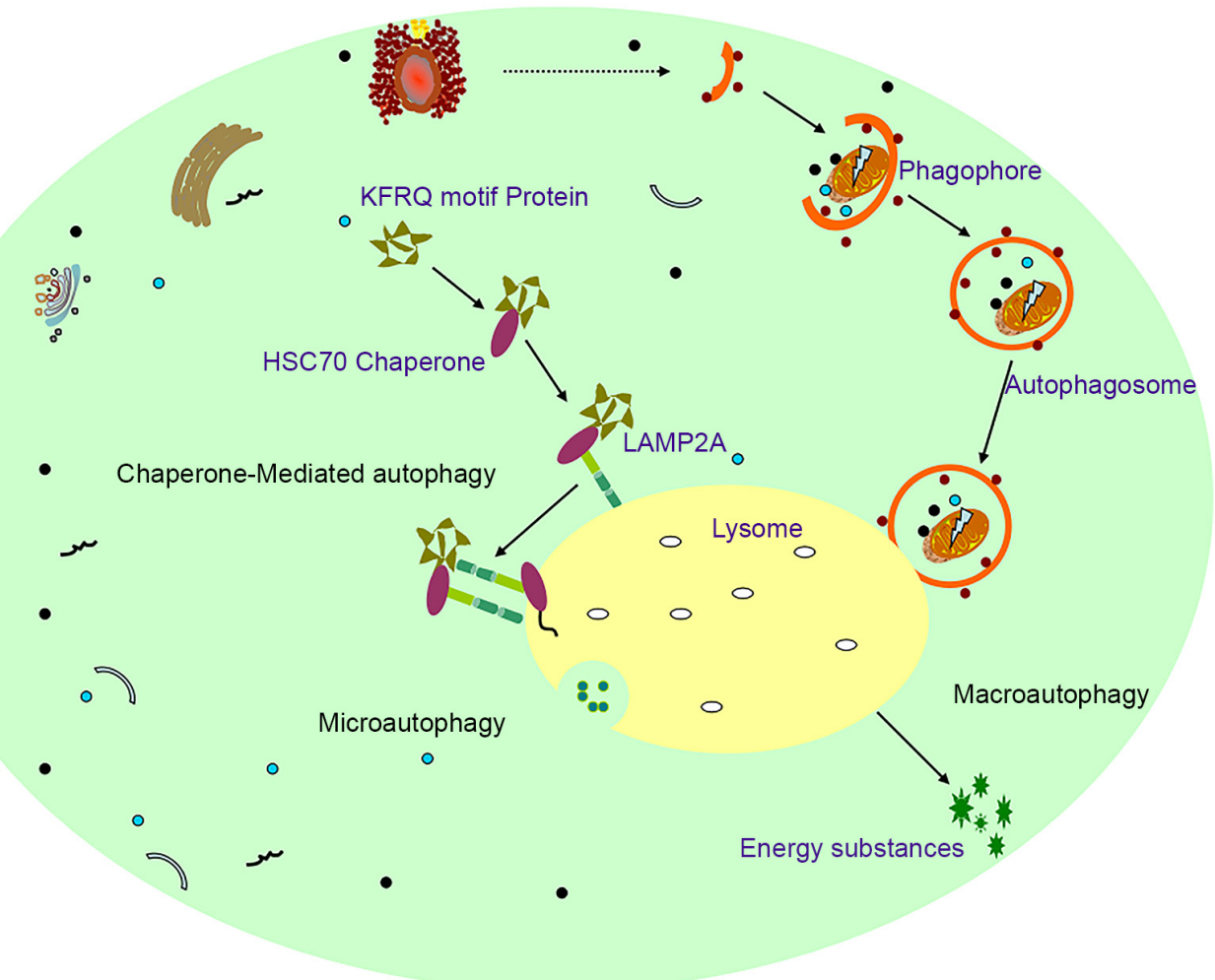

Figure 1. Classification and initiation of autophagy. Autophagy is classified as macroautophagy, chaperone-mediated autophagy and microautophagy. The engulfed organelles/proteins or other components are degraded into amino acids or other raw materials that can be used for cell survival or to maintain the nutritional state of the cell, allowing the cell to survive under various adverse conditions.

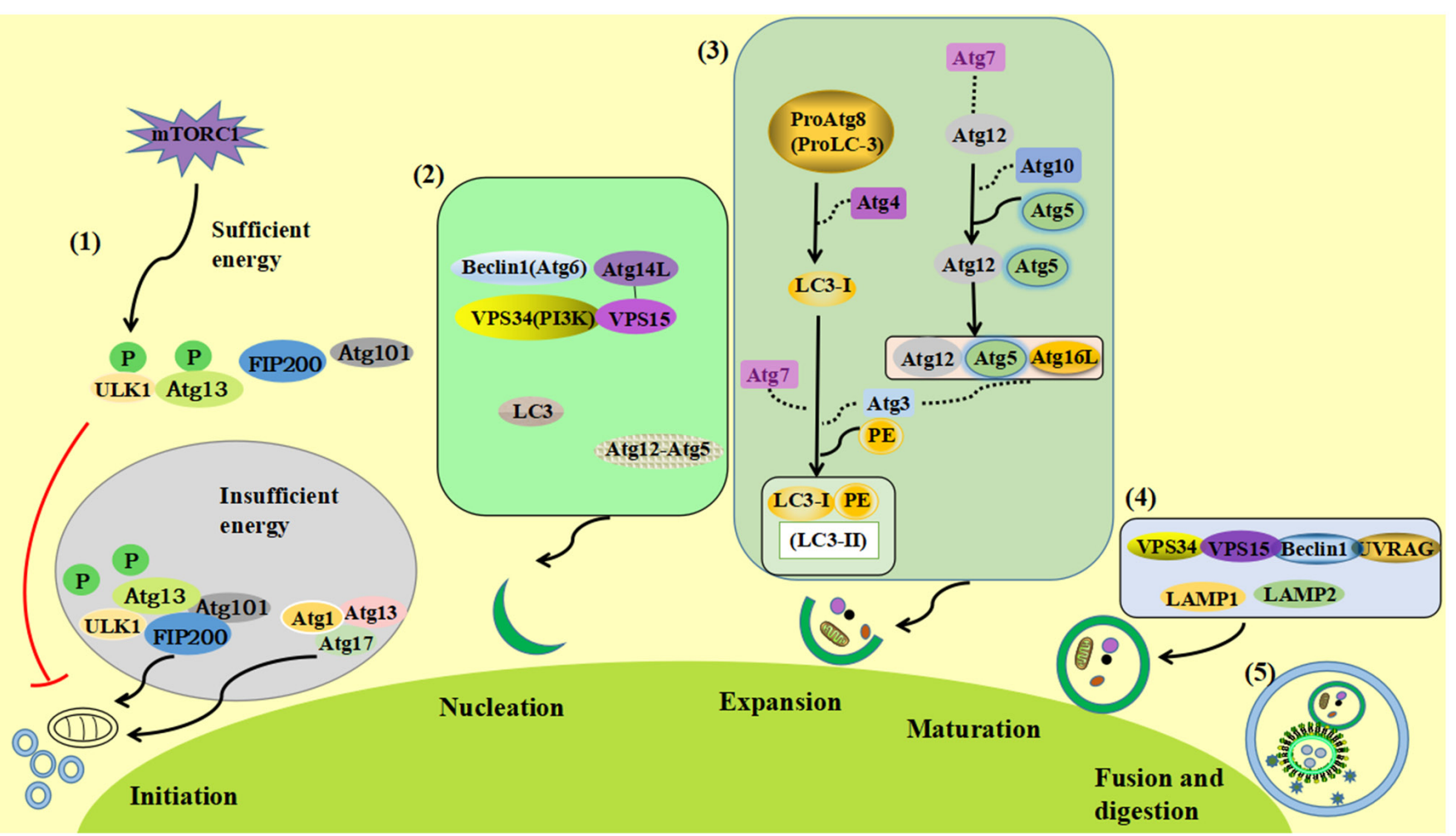

Figure 2. The initiation and occurrence of autophagy. Autophagy includes the following stages: autophagy induction, nucleation, autophagosome extension, autophagosome maturation and autophagosome lysis. (1) The ULK1-Atg13-FIP200-Atg101 complex is involved in the induction of autophagy. (2) Formation of the Beclin1 (Atg6)-Atg14L-VPS15-VPS34 (PI3K) complex and the recruitment of Atgs. (3) Modification of the Atg5-Atg12 and LC3 systems. (4) SNARE and the Vps34-Vps15-Beclin1-UVRAG complex participate in the maturation of autophagosomes. (5) Acid hydrolases in autophagic lysosomes degrade the contents of vesicles. 


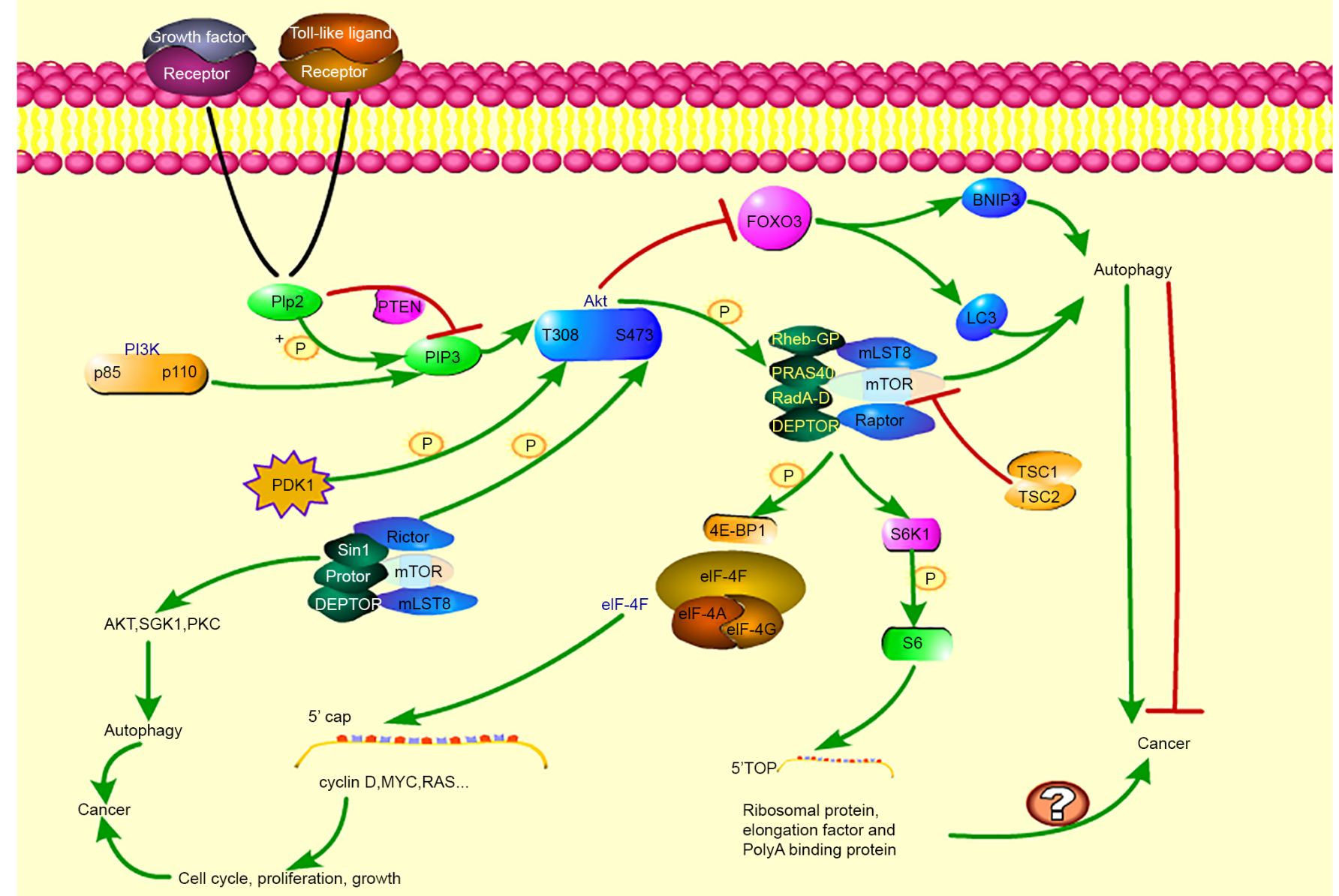

Figure 3. The mTOR/PI3K/Akt signaling pathway in autophagy and cancer. mTOR generally forms two complexes: mTORC1 consists of central proteins (mTOR, mLST8 and Raptor) and associated proteins (PRAS40, DEPTOR, RadA-D and Rheb-GP), and mTORC2 consists of central proteins (mTOR, mLST8 and Rictor) and related proteins (Sin1 and Protor and DEPTOR). mTOR regulates autophagy through two mechanisms. mTORC1 acts on and S6K1 through signal transduction pathways and initiates the transcription and translation of related genes, thereby regulating autophagy. mTOR kinase may also directly affect Atg to regulate autophagy. 4E-BP1, eIF-4E-binding protein 1.

development of tumors involves numerous signaling pathways and associated factors. Therefore, a more comprehensive review of autophagy and tumor-related signaling pathways is required to understand the pathogenesis and treatment of cancer.

The mTOR/PI3K/AKT signaling pathway in autophagy and cancer. mTOR, a highly evolutionarily conserved kinase, is important for cell proliferation, growth and metabolism (29). Early studies have demonstrated that rapamycin, an mTOR inhibitor, may induce autophagy (30). A previous study reported that the mTOR signal transduction pathway is associated with autophagy regulation (31). There are two types of mTOR complexes, rapamycin-sensitive mTORC1 and rapamycin-insensitive mTORC2 $(32,33)$. Rapamycinsensitive mTORC1 is composed of mTOR, mLST8, Raptor, PRAS40, DEPTOR, RadA-D and Rheb-GP and mTORC2 is composed of mTOR, mLST8, Rictor and related proteins (Sin1 and Protor, DEPTOR; Fig. 3) (34). mTOR regulates autophagy through two mechanisms. mTORC1 acts on 4E-BP1 (eIF-4E-binding protein 1) and S6K1 through the signal transduction pathway and may initiate transcription and translation of associated genes and regulate autophagy (35). mTOR kinase may also directly act on Atg and regulate autophagy (36). 4E-BP1 is a negative regulator of translation and may be phosphorylated and inactivated by mTORC1. The inactivated 4E-BP1 dissociates from eIF-4E, thereby activating eIF-4E. EIF-4E binds with eIF-4A and eIF-4G to form an eIF-4F complex. The EIF-4F complex binds to the cap structure at the $5^{\prime}$ end of target mRNA, which promotes the initiation of translation. EIF-4E may regulate the translation of numerous proteins, including cyclin D-MYC and RAS, which are closely associated with cancer cell growth, proliferation and cell cycle regulation, thereby affecting cancer progression $(37,38)$. S6K1 is a serine/threonine kinase with multiple phosphorylation sites that is directly or indirectly regulated by $\mathrm{mTORC} 1$ and participates in the regulation of autophagy (30). S6K1 may phosphorylate and activate 40S ribosomal protein S6. Activated S6 may improve the translation efficiency of 5' terminal oligopyrimidine bundle (TOPS) RNA. 5'Top mRNA accounts for 15-20\% of total intracellular RNA and encodes numerous components required for protein translation, including ribosomal proteins, elongation factors and polyA-binding proteins. A previous study demonstrated 
that abnormal synthesis of these proteins is associated with cancer (39). Members of the AGC protein kinase family, including Akt, SGK1 and PKC, are known substrates of mTORC2 and serve important roles in regulating cytoskeletal remodeling and autophagy (40). The expression of the tumor suppressor FOXO3a is usually downregulated in cancer (41). Activated FOXO3 may induce autophagy by enhancing the transcription of autophagy-related genes LC3 and BNIP3, while mTORC2 blocks the activation of FOXO3 by activating Akt (42). Therefore, FOXO3a is a key molecule connecting autophagy and cancer, and its expression may be regulated by regulating autophagy-related signaling pathways, suggesting that FOXO3a may be a target for the treatment of cancer.

When a growth factor or a Toll-like ligand binds to a growth factor receptor or a Toll-like receptor, p85 is activated, and p110 is recruited, thereby activating PI3K and then catalyzing PIP2 phosphorylation on the plasma membrane to produce the second messenger PIP3, recruiting Akt (43). PTEN is a phosphatase that inhibits the transition of PIP2 to PIP3, thereby preventing PIP3 from recruiting Akt to the membrane, inhibiting Akt activation by preventing phosphorylation (44). PDK1 is a kinase. When Akt is recruited to the membrane, PDK1 phosphorylates Akt at threonine 308 (T308), and mTORC2 and other kinases phosphorylate Akt at serine 473 (S473). When these two sites are phosphorylated, Akt is fully activated, and PRAS40 is phosphorylated, thereby alleviating PRAS40mediated inhibition of mTORC1 (45). Following mTORC1 activation, some of the aforementioned regulatory responses take place. In addition, the TSC 2 and TSC 1 complexes, which are encoded by the Tsc1 and Tsc2 genes, respectively, may inactivate Rheb, inhibiting the activity of mTORC1, and thereby promoting autophagy (46). Activated Akt may phosphorylate TSC2 and prevent the formation of the TSC complex, which further leads to the activation of mTORC1, thereby inhibiting autophagy (47). It has been demonstrated that the mTOR/PI3K/Akt signaling pathway is triggered in tumor cells and is considered to be a key therapeutic target for the treatment of various cancer types (48). Han et al (49) demonstrated that $\beta$-rapazone may block the mTOR/PI3K/Akt signaling pathway, induce autophagy, and ultimately inhibit the migration and invasion of nasopharyngeal carcinoma cells. In addition, angiogenesis may provide nutrition and oxygen to tissues, which are essential for tumor growth and metastasis. It has been demonstrated that dihydroartemisinin (DHA) may induce autophagy in human umbilical vein endothelial cells by inhibiting the Akt/mTOR signaling pathway (50). It has been reported that angiogenesis is a major cause of cancer, and DHA is an effective antiangiogenic agent (51). Recent studies have demonstrated that angiogenesis is closely associated with autophagy (52). Antitumor therapy by inhibiting angiogenesis is also a promising strategy. In numerous cancer types, protective autophagy induces chemical resistance to various chemotherapeutic agents. Therefore, the efficacy of chemotherapeutic agents in numerous cancer types is limited by spontaneous protective autophagic induction, and chemical resistance may be overcome by studying autophagy pathways and properly regulating autophagy levels. Liu et al (53) reported that the combination of 9za with autophagy inhibitors (including chloroquine or 3-methyladenine) exhibited higher cytotoxicity and apoptosis than 9za alone and reported that the Akt/mTOR axis was associated with 9za-induced autophagy (53). In addition, PDK1 overexpression leads to increased phosphorylation of PDK1 and Akt, and blockade of 9za-mediated autophagy (53). The regulation of autophagy contributes toward the expression of tumor suppressor proteins or oncogenes. Tumor suppressors are negatively regulated by mTOR, leading to autophagy induction and cancer initiation inhibition. By contrast, oncogenes may be activated by mTOR, class I PI3K and Akt, leading to autophagy inhibition and cancer development. The induction of autophagy has a positive regulatory effect on cancer chemotherapy resistance; therefore, reducing chemotherapy resistance by inhibiting autophagy is one of the strategies that may be considered in cancer treatment. Furthermore, studies have reported that abnormal PI3K/Akt/mTOR signaling is associated with cancer cell growth, survival, movement and resistance to targeted therapy (54-56). It was demonstrated that in head and neck squamous cell carcinoma, the mutation rate of the mTOR genome reached $80-90 \%$ (57). In addition, previous studies have reported that in gastric cancer, breast cancer, prostate cancer, endometrial cancer, cholangiocarcinoma and bladder cancer, inhibiting the mTOR signaling pathway may inhibit cancer progression or has a synergistic effect with current conventional treatments (including radiotherapy and chemotherapy), enhancing sensitization and efficacy (58-63). mTOR is a key factor in this pathway. A previous study has demonstrated that there is inevitable resistance to first- and second-generation mTOR inhibitors, which may be associated with drug-resistant mutants and the induction of autophagy (64). However, the third-generation mTOR inhibitor, Rapalink, (which inhibits both sites of mTOR at the same time) may enter cancer cells, inactivate mTOR signaling, and decrease resistance to first- or second-generation mTOR inhibitors (64). Akt inhibitor VIII (AKTi-1/2) may reversibly inhibit Akt, and when combined with other inhibitors, it synergistically enhances the anticancer effect (65). Therefore, the majority of studies have focused on PI3K/Akt/mTOR signaling pathway inhibitors. Unfortunately, the majority of mTOR signaling pathway inhibitors are in clinical trials, and numerous challenges need to be overcome if these treatments are to be used clinically. A previous study reported that, in patients with HER2-positive cancer, inhibiting the mTOR pathway alone may activate autophagy, causing cancer cells to escape and develop drug resistance (66). Therefore, it is necessary to investigate the inhibition of other signal transduction pathways, dual pathway inhibition or multiple pathway inhibition to achieve the inhibition of cancer progression. To date, no typical biomarkers have been identified to predict the PI3K/Akt/mTOR signaling pathway inhibitory responses or drug resistance. Therefore, targeting the PI3K/Akt/mTOR signaling pathway in cancer treatment requires comprehensive investigation.

The AMPK signaling pathway in autophagy and cancer. As a cellular energy receptor, AMPK serves a key role, not only in the regulation of cellular energy homeostasis, but also in carcinogenesis and anticancer drug resistance (67). AMPK may form a heterotrimeric complex containing a catalytic $\alpha$-subunit and regulatory $\beta$-and $\gamma$-subunits. Following binding to the $\gamma$-subunit, AMP allosterically activates the complex, resulting in substrate phosphorylation at threonine 172 and 


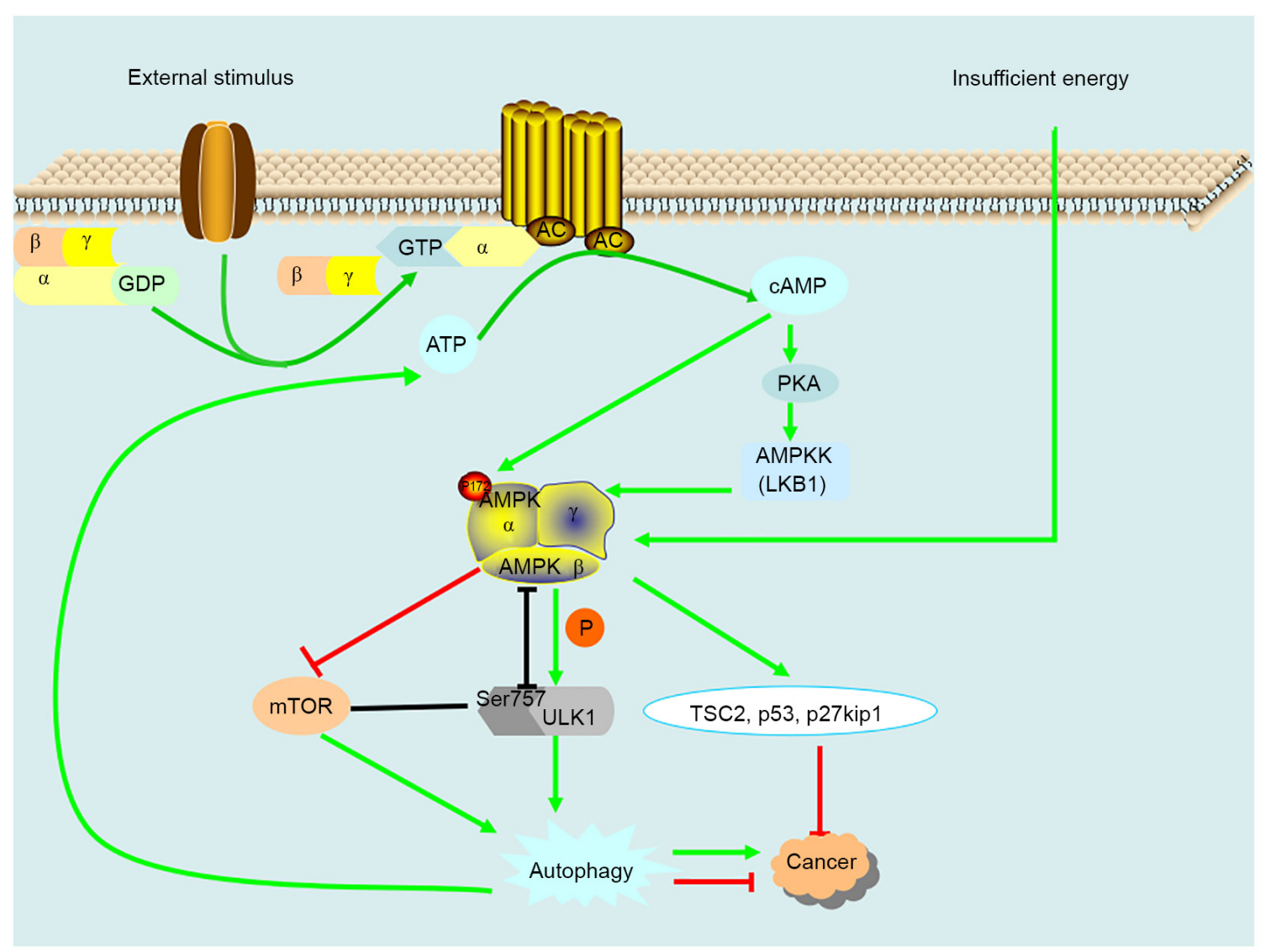

Figure 4. AMPK signaling pathway in autophagy and cancer. AMPK may form a heterotrimeric complex that contains a catalytic $\alpha$-subunit and regulatory $\beta$ - and $\gamma$-subunits. Following AMP binding to the $\gamma$-subunit, the allosteric activation complex is phosphorylated at threonine 172 and is phosphorylated by upstream LKB1 at the activation loop of the alpha subunit, which induces autophagy. AMPK can also act on the downstream factors, TSC2, p53 and p27kip1, and mediate cancer formation and development.

further phosphorylation by upstream LKB1 in the activation ring of the $\alpha$-subunit (Fig. 4) (68). When cells are stimulated, extracellular signaling molecules first bind to the receptor to form a complex and then activate the Gs protein on the cell membrane. The activated Gs protein reactivates adenylate cyclase (AC) on the cell membrane to catalyze the removal of pyrophosphate from ATP to produce cAMP. The decreased cellular energy state enhances the phosphorylation and activation of AMPK by LKB1, and following activation, AMPK catalyzes the phosphorylation of ULK1, which induces autophagy (69). Induced autophagy removes the accumulated unwanted components that cause inflammation, stimulate ROS, trigger cell death and induce genomic instability, all of which contribute toward cancer. Therefore, AMPK-induced autophagy may prevent the occurrence and development of tumors. In addition, induced autophagy may also provide nutrients for tumor cells and aid tumors in adapting to adverse environments. It has been demonstrated that in breast cancer cells, parthenolide activates the apoptosis pathway and AMPK-autophagy survival pathway through the production of ROS. Inhibition of AMPK or autophagy may potentially enhance the anticancer effect of parthenolide on breast cancer cells (70). In addition, AMPK can also act on the downstream factors TSC2, p53 and p27kip1 (71). LKB1 is the upstream tumor suppressor of AMPK, and TSC2, p53 and p27kip1 are downstream tumor suppressor genes, indicating that AMPK has a certain role in tumor inhibition.
Notably, AMPK is a key factor in the response to metabolic stress and the maintenance of energy homeostasis. As AMPK is able to support the proliferation of cancer cells by regulating energy metabolism, the AMPK pathway has attracted much attention in the treatment of cancer. In thyroid cancer, the AMPK pathway is highly activated (72). It was demonstrated that inhibiting the AMPK pathway may inhibit cancer. JQ1 may induce autophagy by activating the LKB1/AMPK pathway, thereby inhibiting cancer cell proliferation (73). In addition, NPC-26 kills human colorectal cancer cells by activating AMPK signaling (74). Therefore, AMPK and its pathways are expected to serve as therapeutic targets for the treatment of a variety of cancer types. In summary, the role of the AMPK pathway in autophagy and cancer is complicated, but AMPK pathway inhibition is more conducive to cancer suppression than activation.

The MAPK signaling pathway in autophagy and cancer. MAPK is a serine/threonine protein kinase that primarily includes three subgroups: ERK, JNK/SAPKII and p38-MAPK (Fig. 5). MAPK may regulate the expression of downstream genes by regulating $\mathrm{B}$ lymphocyte tumor- 2 gene (Bcl-2) family proteins. $\mathrm{Bcl}-2$ family proteins are key regulators in the disposal of abnormal cells and participate in almost all cell pathological and physiological processes, including cell cycle regulation, cell survival and death, gene expression, and cell movement (75). JNK regulates autophagy through 


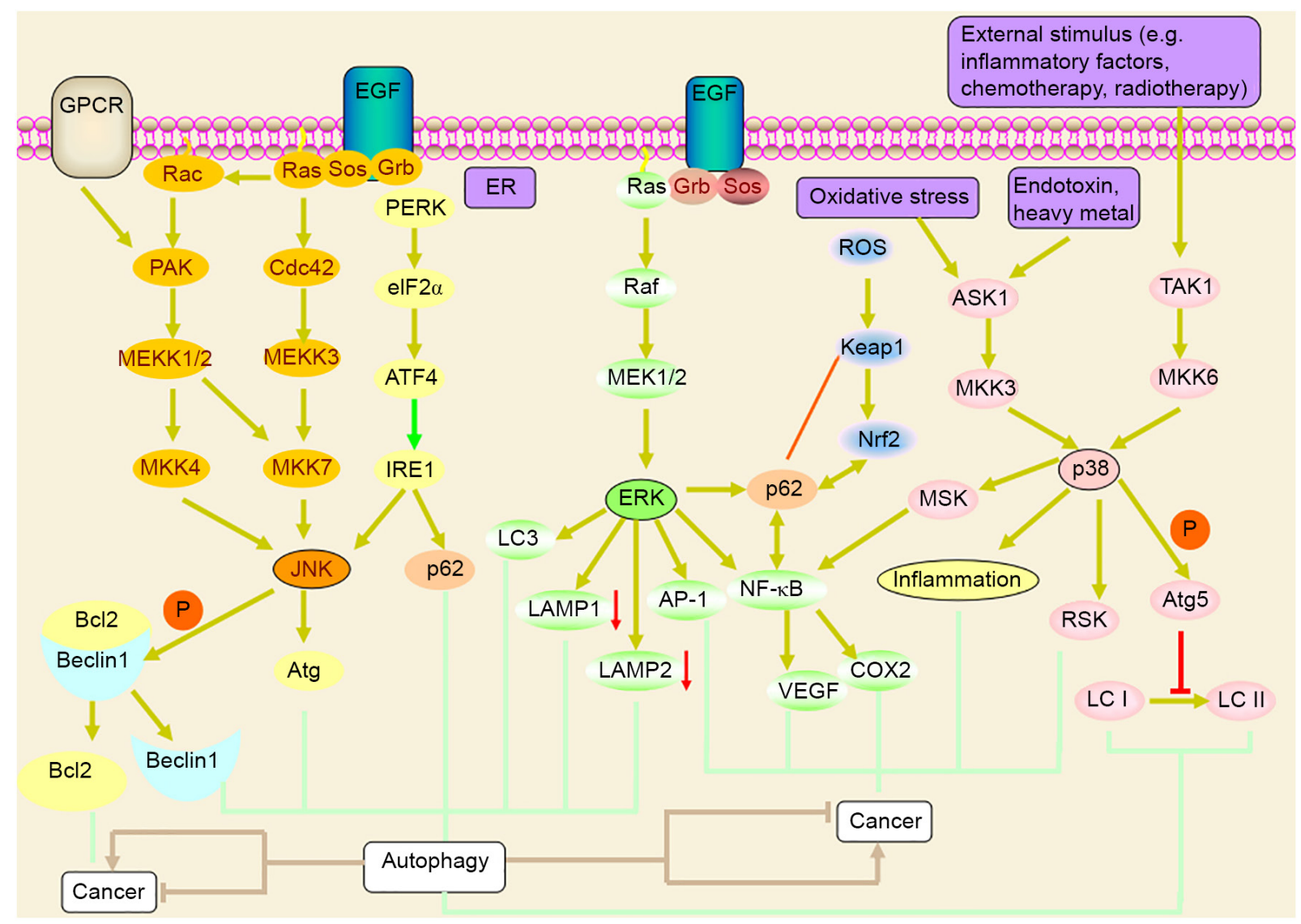

Figure 5. MAPK signaling pathway in autophagy and cancer. The MAPK signaling pathway mainly includes three subfamilies: ERK, JNK/SAPKII and p38-MAPK. JNK may regulate autophagy through Beclin-dependent and -independent signaling. When cells are stimulated by signals from growth factors, mitogens and stimuli, the ERK pathway is activated by the Ras-Raf-MEK1/2-ERK cascade. Extracellular stimulation (including inflammatory factors, endotoxin, osmotic pressure, chemotherapy and ultraviolet) or intracellular stimulation (including oxidative stress and heavy metals) activates MAPK p38 through the TAK1-MKK6-p38 and ASKK1-MKK3-p38 cascades, respectively.

Beclin-dependent and -independent signaling (76). ER stress upregulates p62 expression through the PERK-mediated eIF2 $\alpha$-ATF4 pathway and activates the ER transmembrane sensor. Inositol requires enzyme 1 (IRE1) to activate Jun $\mathrm{N}$-terminal kinase (JNK), and JNK activation may inhibit/ phosphorylate the antiapoptotic protein $\mathrm{Bcl} 2$, which leads to the dissociation of Bcl2 from Beclin-1, resulting in autophagic flux. Pan et al (77) found that Prodigiosin-induced endoplasmic reticulum stress could lead to breast cancer cell death through the PERK-mediated eIF2 $\alpha$-ATF4 pathway, in which IRE1-JNK mediates Bcl2-induced cell death. However, JNK mediates the increase in $\mathrm{Bcl} 2$ and protective autophagy, resulting in increased autophagic flux and the induction of therapeutic resistance. Therefore, the therapeutic agent Prodigiosin, could be used in combination with autophagy inhibitors to inhibit associated autophagic flux, which may improve treatment efficacy. P62 is a ubiquitin-binding protein that is closely associated with the ubiquitination of proteins. P62 is involved in the regulation of a variety of cellular signal transduction pathways and autophagy (78). In autophagy, p62 binds to ubiquitin, forms a complex with LC3-II located on the autophagic membrane, and is degraded in the autophagic lysosome. Therefore, when autophagy occurs, p62 protein is continuously degraded in the cytoplasm; when autophagic activity is weakened and autophagy is deficient, p62 protein will accumulate in the cytoplasm. P62 is one of the marker proteins that reflects autophagic activity. The P62 level indirectly reflects the level of autophagosome clearance. A large number of studies have demonstrated that high expression of p62 is associated with poor prognosis in colon cancer, nonsmall cell lung cancer and breast cancer (79-81). Therefore, p62 may be an important target for the treatment of these cancer types. By contrast, JNK may upregulate the expression of Atg and promote autophagy. Chen et al demonstrated that tumor necrosis factor-related apoptosis-inducing ligand (TRAIL) promoted autophagy in A549 cells by regulating the expression of ATG through the JNK pathway (82). Autophagy inhibition may inhibit proliferation and enhance apoptosis in A549 cells induced by TRAIL (82). A previous study have demonstrated that JNK has a significant oncolytic effect, and autophagy inducers acting on the JNK/Beclin-1 axis may enhance this oncolytic effect (83). Notably, JNK is a potential molecular target for tumor therapy. When cells are stimulated by growth factors, mitogens and environmental stimuli, they activate the ERK pathway through the Ras-Raf-MEK1/2-ERK cascade and act on nuclear transcription factors, including AP-1 and $\mathrm{NF}-\kappa \mathrm{B}$ to regulate gene expression (84). In addition, the activation of ERK may promote the expression of LC3 and p62, promote autophagy, and downregulate the expression of LAMP1 and LAMP2, thereby inhibiting the binding of lyso- 
somes to autophagosomes and inhibiting the degradation of autophagosomes (85). Mou et al (86) reported that Berbamine exhibited anticancer effects on human HT-29 colon cancer cells by inhibiting the MEK/ERK pathway and cell migration, and inducing autophagy and apoptosis. Therefore, MEK/ERK is expected to be a therapeutic target for colon cancer.

Oxidative stress is one of the causes of autophagy. In vivo ROS accumulation not only activates autophagy, but also the Keap1-Nrf2 oxidative stress signaling pathway (87). P62 not only functions as one of the key factors in autophagy, but also regulates $\mathrm{Nrf} 2$ and $\mathrm{NF}-\kappa \mathrm{B}$, which induce p62 gene transcription, and endoplasmic reticulum stress may induce p62 mRNA expression. The accumulation of p62 may lead to the activation of $N F-\kappa B$, and $N F-\kappa B$ may induce the expression of VEGF and promote angiogenesis, thereby promoting the occurrence of cancer (88). In addition, $\mathrm{NF}-\kappa \mathrm{B}$ may promote tumor growth by regulating the expression of COX2 and other genes (89). When autophagy is disturbed, p62 competitively binds with Keap1 to block the Keap1-Nrf2 pathway and increase Nrf2 signal transduction. P62 is the transcriptional target of $\mathrm{Nrf} 2$. Under oxidative stress conditions, Nrf2 induces increased p62 to reactivate Nrf2. At the same time, the increase in p62 promotes autophagy (87). ABRUS lectin (AGG) is a heterotetramer type II ribosome-inactivating protein isolated from Abrus precatorius seeds. AGG induces autophagy in the human tongue phosphorous cancer CAL33 cell line through ROS and regulates NRF2 through p62 (90). Therefore, AGG induces NRF2 degradation via autophagy and leads to ROS accumulation-dependent apoptosis, which may be used in the treatment of oral cancer. The binding of Keap1 and Nrf2 causes abnormal activation of Nrf2 in cancer cells. Unregulated Nrf2 may make cancer cells highly tolerant to anticancer drugs and ROS and stimulate metabolic reprogramming in cancer cells. Metabolic reprogramming is one of the main signs of cancer. Autophagy and oxidative stress disorders may lead to the accumulation of unfavorable oxidation products in cells, which may lead to cancer. Therefore, ensuring the balance between autophagy and oxidative stress is one of the strategies for the prevention and treatment of cancer. Tyrosine 180 and threonine 182 of p38 MAPK are located in the VIII domain. The activation of MAPK p38 requires dual phosphorylation of tyrosine and threonine. External stimulation (including inflammatory cytokines, endotoxin, osmotic pressure, chemotherapy and ultraviolet radiation) or intracellular stimulation (including oxidative stress and heavy metals) activate MAPK p38 through the TAK1-MKK6-p38 and ASKK1-MKK3-p38 cascades, respectively. Phosphorylation of Atg 5 inhibits autophagic membrane extension and the transformation of LCI to LCII, thereby inhibiting the occurrence of autophagy $(91,92)$. By contrast, Atg5 phosphorylation regulates downstream MSK and RSK protein kinases, thereby regulating transcription and translation (93). In addition, certain tumorrelated proteins/factors, including p53 Magi, Myc and CHOP, are downstream of MAPK p38 $(91,94)$. Therefore, MAPK p38 is a candidate tumor treatment target.

Autophagy exhibits dual effects on cells, not only protecting cells, but also leading to cell death. The production of tumor-associated ROS may be stimulated by endogenous and exogenous factors. Endogenous factors generally include mitochondrial products and nutrient deficiency, and exogenous factors include chemotherapy and radiotherapy. ROS have been suggested to induce or mediate the activation of MAPK family members and serve important roles in autophagy and apoptosis (95). It is known that there is a series of complex signal transduction pathways and interactions between ROS and autophagy that regulate autophagy. In response to cellular stress, there are checks and balances between the two responses; ROS may participate in the induction of autophagy, and conversely, autophagy may control the level of ROS (96). In addition, ROS-mediated autophagy activation mainly serves a cytoprotective role in starvation conditions. However, in certain cases, ROS may induce cell damage and participate in certain signal transduction pathways, leading to autophagic death. JNK activation is involved in the apoptosis- and autophagymediated responses to various stress signals (97). JNK may mediate the phosphorylation of the antiapoptotic protein, $\mathrm{Bcl}-2 / \mathrm{Bcl}-\mathrm{xL}$, to change the MMP. In this respect, the mitochondrial dysfunction induced by lutein VI may be associated with the JNK-mediated apoptotic response. JNK activation also contributes toward autophagy induction. Lutein VI induces G2/M arrest, apoptosis and autophagy in human osteosarcoma cells by activating the ROS/JNK pathway (98). Chitooligosaccharide (COS) exerts significant antitumor activity on human cervical cancer $\mathrm{C} 33 \mathrm{~A}$ cells by activating oxidative stress and mitochondrial apoptosis and autophagy signal transduction. Ubenimex may inhibit the proliferation of pituitary adenoma GH3 and MMQ cells, and induce apoptosis and autophagy, which may be associated with the activation of the ROS/ERK1/2 pathway (99). These findings provide novel perspectives for the possible application of Ubenimex in the chemotherapeutic treatment of pituitary adenomas. In addition, autophagy is associated with cancer treatment resistance. It has been reported that breast cancer MCF-7 cells are resistant to tamoxifen through autophagy induced by $\mathrm{p} 38 / \mathrm{c}-\mathrm{JNK}$ (100). A previous study reported that ECZ induces apoptosis in mouse colon cancer CT-26 cells through a caspase-dependent pathway and triggers autophagy by increasing the formation of autophagosomes, and the production of ROS serves a key role in this process (101). Inhibition of autophagy enhances ECZ-induced apoptosis, which is due to increased ROS production, suggesting that autophagy may serve a cytoprotective role by resisting apoptosis (101). Therefore, ECZ may be used in combination with autophagy inhibitors for the chemoprevention of cancer or as a chemotherapeutic agent. By examining ROS production, apoptosis and autophagy, it has been demonstrated that regulating the apoptosis-autophagy balance in cells treated with ultralong silver nanowires may protect A549 cells from ROS accumulation and nutrient deficiency ultralong nanowire stimulation (102). Therefore, autophagy serves a role in cytoprotection, which is also a factor leading to the therapeutic resistance of cancer cells. In general, ROS serves important roles in apoptosis and autophagy signal transduction, and the production of ROS selectively induces cancer cell death. Autophagic cell death leads to a significant decrease in the number of cancer cells, but as autophagic cell death generally occurs in normal cells rather than cancer cells, the inactivation of autophagic cell death remains an important cause of tumor formation. 
Table I. Autophagy-associated antineoplastic agents.

\begin{tabular}{|c|c|c|c|c|}
\hline Agent & Tumor (cell) type & Action target & $\begin{array}{l}\text { Autophagy activator } \\
(+) / \text { inhibitor }(-)\end{array}$ & Ref. \\
\hline Everolimus tablets & $\begin{array}{l}\text { Human breast cancer cells } \\
\text { (MCF-10DCIS) }\end{array}$ & Inhibit mTOR & + & $(103)$ \\
\hline Venetoclax (ABT199) & Mammary cancer cells & Inhibit Bcl-2; induce autophagy by & + & (104) \\
\hline AT-101, obatoclax & $\begin{array}{l}\text { MCF7 cells, human acute } \\
\text { T lymphoblastic leukemia } \\
\text { cells }\end{array}$ & $\begin{array}{l}\text { interfering with the interaction } \\
\text { between Beclin1 and Bcl-2 }\end{array}$ & + & $(105,106)$ \\
\hline $\begin{array}{l}\text { Rapamycin } \\
\text { (AY 22989; sirolimus) }\end{array}$ & Liver cancer HepG2 cells & Inhibit mTOR & + & (107) \\
\hline 3-MA & Small cell lung cancer & $\begin{array}{l}\text { Inhibit the PI3K/Akt signaling } \\
\text { pathway }\end{array}$ & - & $(108)$ \\
\hline LY294002 & Human glioblastoma cells & $\begin{array}{l}\text { Inhibit the PI3K/Akt signaling } \\
\text { pathway }\end{array}$ & - & (109) \\
\hline Bafilomycin A1 & Glioma cell lines & Selectively inhibit $\mathrm{H}^{+}$-ATPase & - & (110) \\
\hline Autophinib & MCF7-LC3 cells & VPS34 & - & (111) \\
\hline ROC-325 & Renal cell carcinoma & LC3B and p62 & - & (112) \\
\hline IITZ-01 & $\begin{array}{l}\text { Lung, colon and breast } \\
\text { cancer cells }\end{array}$ & $\begin{array}{l}\text { Enhance autophagosome formation } \\
\text { as indicated by increased } \\
\text { expression of LC3-II }\end{array}$ & - & (113) \\
\hline Daurisoline & HeLa and MEF cells & Destroy lysosomes & - & (114) \\
\hline 3BDO & Lung cancer A549 cells & Activate mTOR kinase & - & (115) \\
\hline 9f & Breast cancer & BRD4 & - & (94) \\
\hline $\mathrm{CQ}, \mathrm{HCQ}$ & $\begin{array}{l}\text { Human lung cancer cells, } \\
\text { human glioblastoma cells }\end{array}$ & $\begin{array}{l}\text { Inhibit the fusion of } \\
\text { autophagosomes and lysosomes }\end{array}$ & - & $(110,116)$ \\
\hline Spautin-1 & HepG2 cells & $\begin{array}{l}\text { Inhibit the deubiquitination activity } \\
\text { of USP10 and USP13 }\end{array}$ & - & (117) \\
\hline
\end{tabular}

3-MA, 3-methyladenine; CQ, chloroquinine; HCQ, hydroxychloroquine.

\section{Autophagy-associated antineoplastic agents}

The basal level of autophagy suppresses tumorigenesis by decreasing damaged organelles and proteins and other unwanted components to maintain cellular homeostasis. However, autophagy disorders positively regulate the occurrence and development of tumors. Due to the association between autophagy and tumor occurrence and development, a series of autophagy regulators have been developed to treat tumors (Table I).

A number of autophagy regulators, including everolimus tablets, venezuela, AT-101, rapamycin, 3-MA, LY294002, bafilomycin A1, autophinib, ROC-325, IITZ-01, daurisoline, 3BDO, 9f, chloroquine (CQ), hydroxychloroquine (HCQ) and spautin-1, are used to treat cancer (103-117). CQ and HCQ are lysosome inhibitors that inhibit autophagy and induce the accumulation of autophagosomes by altering lysosomal $\mathrm{pH}(110,117)$. Preclinical studies have demonstrated that CQ or HCQ may inhibit the growth of cancer cells by inhibiting autophagy in bladder cancer, pancreatic cancer, lung cancer and glioma $(110,116,118)$. In addition, a number of studies have reported that these reagents enhance the therapeutic effects of radiotherapy and chemotherapy by inhibiting autophagy-mediated anticancer therapy $(53,111,112)$. Therefore, the development of autophagy-specific inhibitors is a novel therapeutic strategy for anticancer therapy.

Under cellular stress conditions, including nutrient deficiency or starvation, hypoxia, oxidative stress, pathogen infection, radiation or anticancer drug therapy, the level of autophagy increases, which enhances cell adaptability and viability and serves a role in cell protection. For solid tumors with low blood supply, autophagy provides energy for cancer cells, but this is not always the case. Autophagy also serves a different role in different types of cancer. AT-101 induces autophagy via Beclin1-dependent or Beclin1-independent pathways; induces survival-mediating protective autophagy in Burkitt lymphoma, breast cancer, cervical cancer and non-small cell lung cancer; and induced autophagic death in prostate cancer cells, malignant peripheral schwannomas and gliomas $(105,106)$. In addition, different types of tumors have different autophagic activities. In ovarian cancer, lung cancer, brain glioma and esophageal cancer, the protein expression of Beclin1 and autophagic activity are decreased $(119,120)$. However, in nasopharyngeal carcinoma, the prognosis of the 
group with high Beclin1 expression combined with radiotherapy was worse than that of the group with low Beclin1 expression. This effect may be due to the decrease in microvessel density in tumor tissue following radiotherapy, resulting in tissue hypoxia, thereby inducing autophagy and promoting tumor survival in a hypoxic environment. Therefore, the sensitivity of cancer cells to radiotherapy is decreased (121). Autophagy function was decreased and cell necrosis was increased, promoting tumor progression. Beclin1 deletion decreases autophagy, thereby promoting the occurrence and development of tumors. Tumor cells degrade unwanted substances through autophagy to generate nutrients and decrease energy consumption, which is conducive to tumor survival; high autophagic activity may confer a survival advantage in harsh environments but may weaken the effect of radiotherapy. Therefore, when developing tumor-associated autophagy inhibitors/activators, comprehensive consideration should be given to different types of tissues and different types of tumors. In numerous cancer types, protective autophagy induces resistance to various chemotherapeutic agents. Therefore, the efficacy of chemotherapeutic agents in numerous cancer types is limited by spontaneous protective autophagy induction, and chemoresistance may be overcome by studying autophagic pathways and effectively regulating autophagy levels.

\section{Conclusions}

In conclusion, the signaling pathways and factors associated with autophagy and cancer are intertwined. Tumor suppressors may serve a dual role in autophagy. The occurrence of autophagy may promote cancer and inhibiting autophagy may inhibit cancer. The occurrence of autophagy may also inhibit cancer progression. Activation of autophagy may inhibit cancer, but at the same time, autophagy is a key factor in the development of drug resistance. Therefore, it is also necessary to prevent the development of drug resistance, including through the inhibition of multiple signal transduction pathways, to increase the inhibition of cancer and inhibit drug resistance. The mTOR/PI3K/Akt, AMPK and MAPK signaling pathways and their upstream and downstream factors all serve important roles in cancer and autophagy, and no reliable evidence has been collected for the reversal of these pathways. Therefore, reasonable analysis, evaluation and identification of cancer types, staging and the tumor microenvironment contribute toward the selection of therapeutic targets and prognostic markers.

\section{Acknowledgements}

Not applicable.

\section{Funding}

The present study was supported by grants from the Inner Mongolia Autonomous Region Higher Education Research Project of China (grant no. NJZY19106) and the National Natural Science Foundation of China (grant no. 81660468).

\section{Availability of data and materials}

Not applicable.

\section{Authors' contributions}

CC wrote the manuscript. HG constructed and edited the figures. XS revised the manuscript. All authors read and approved the final manuscript.

\section{Ethics approval and consent to participate}

Not applicable.

\section{Patient consent for participation}

Not applicable.

\section{Competing interests}

The authors declare that they have no competing interests.

\section{References}

1. Klionsky DJ: Autophagy revisited: A conversation with Christian de Duve. Autophagy 4: 740-743, 2008.

2. Nakatogawa H, Suzuki K, Kamada Y and Ohsumi Y: Dynamics and diversity in autophagy mechanisms: Lessons from yeast. Nat Rev Mol Cell Biol 10: 458-467, 2009.

3. Yamamoto H, Fujioka Y, Suzuki SW, Noshiro D, Suzuki H, Kondo-Kakuta C, Kimura Y, Hirano H, Ando T, Noda NN, et al: The intrinsically disordered protein Atg13 mediates supramolecular assembly of autophagy initiation complexes. Dev Cell 38: 86-99, 2016.

4. Byun S, Lee E and Lee KW: Therapeutic implications of autophagy inducers in immunological disorders, infection, and cancer. Int J Mol Sci 18: 1959-1980, 2017.

5. Ma X, Yin X, Liu H, Chen Q, Feng Y, Ma X and Liu W: Antiproliferative activity of plumbagin (5-hydroxy-2-methyl1,4-naphthoquinone) in human gastric carcinoma cells is facilitated via activation of autophagic pathway, mitochondrialmediated programmed cell death and inhibition of cell migration and invasion. J BUON 24: 2000-2005, 2019.

6. Khan M, Imam H and Siddiqui A: Subversion of cellular autophagy during virus infection: Insights from hepatitis B and hepatitis C viruses. Liver Res 2: 146-156, 2018.

7. Yan X, Zhou R and Ma Z: Autophagy-cell survival and death. Adv Exp Med Biol 1206: 667-696, 2019.

8. Shen MX and Ding JB: Expression levels and roles of EMC-6, Beclin1, and Rab5a in the cervical cancer. Eur Rev Med Pharmacol Sci 21: 3038-3046, 2017.

9. Yu S, Cheng C, Wang J, Wang J, Qu Z, Ren H, Li Y, Ning Q, Chen $\mathrm{M}$ and Hu T: Loss of Beclin1 expression and Nrf2 overexpression are associated with poor survival of patients with non-small cell lung cancer. Anticancer Agents Med Chem 18: 1680-1687, 2018

10. Wu S, Sun C, Tian D, Li Y, Gao X, He S and Li T: Expression and clinical significances of Beclin 1, LC 3 and mTOR in colorectal cancer. Int J Clin Exp Pathol 8: 3882-3891, 2015.

11. Chen JH, Zhang P, Chen WD, Li DD, Wu XQ, Deng R, Jiao L, Li X, Ji J, Feng GK, et al: ATM-mediated PTEN phosphorylation promotes PTEN nuclear translocation and autophagy in response to DNA-damaging agents in cancer cells. Autophagy 11: 239-252, 2015.

12. Wang Z, Wang N, Liu P and Xie X: AMPK and Cancer. Exp Suppl 107: 203-226, 2016

13. Shaw RJ, Bardeesy N, Manning BD, Lopez L, Kosmatka M, DePinho RA and Cantley LC: The LKB1 tumor suppressor negatively regulates mTOR signaling. Cancer Cell 6: 91-99, 2004.

14. Li H, Cao X, Chen X, Yi X, Xia J, Chen J and Yang L: Bufadienolides induce apoptosis and autophagy by inhibiting the AKT signaling pathway in melanoma A-375 cells. Mol Med Rep 20: 2347-2354, 2019.

15. Zhang J, Zhao D, Xie Z and Qi Y: Down-regulation of AKT combined with radiation-induced autophagy and apoptosis roles in MCF-7 cells. Biomed Mater Eng 26 (Suppl 1): S2259-S2265, 2015. 
16. Jiao YN, Wu LN, Xue D, Liu XJ, Tian ZH, Jiang ST, Han SY and Li PP: Marsdenia tenacissima extract induces apoptosis and suppresses autophagy through ERK activation in lung cancer cells. Cancer Cell Int 18: 149, 2018.

17. Zhou J, Chong SY, Lim A, Singh BK, Sinha RA, Salmon AB and Yen PM: Changes in macroautophagy, chaperone-mediated autophagy, and mitochondrial metabolism in murine skeletal and cardiac muscle during aging. Aging (Albany NY) 9: 583-599, 2017.

18. Oczypok EA, Oury TD and Chu CT: It's a cell-eat-cell world: Autophagy and phagocytosis. Am J Pathol 182: 612-622, 2013.

19. Jung CH, Jun CB, Ro SH, Kim YM, Otto NM, Cao J, Kundu M and Kim DH: ULK-Atg13-FIP200 complexes mediate mTOR signaling to the autophagy machinery. Mol Biol Cell 20: 1992-2003, 2009.

20. Zhan ZZ, Chen X and Zhang Y: Autophagy and the relativity of its function. Di Er Jun Yi Da Xue Xue Bao 37: 1189-1194, 2016.

21. Kim SH, Yu HS, Park S, Park HG, Ahn YM, Kang UG and Kim YS: Electroconvulsive seizures induce autophagy by activating the AMPK signaling pathway in the rat frontal cortex. Int J Neuropsychopharmacol 23: 45-52, 2020

22. Chang H, Peng X, Yan X, Zhang J, Xu S, Wang H, Wang Z, Ma X and Gao Y: Autophagy and Akt-mTOR signaling display periodic oscillations during torpor-arousal cycles in oxidative skeletal muscle of Daurian ground squirrels (Spermophilus dauricus). J Comp Physiol B 15: 2019. https://doi.org/10.1007/ s00360-019-01245-5.

23. Kabeya Y, Mizushima N, Yamamoto A, Oshitani-Okamoto S, Ohsumi Y and Yoshimori T: LC3, GABARAP and GATE16 localize to autophagosomal membrane depending on form-II formation. J Cell Sci 117: 2805-2812, 2004

24. Wang Y, Li L, Hou C, Lai Y, Long J, Liu J, Zhong Q and Diao J: SNARE-mediated membrane fusion in autophagy. Semin Cell Dev Biol 60: 97-104, 2016.

25. Cheng X, Ma X, Zhu Q, Song D, Ding X, Li L, Jiang X, Wang X, Tian R, Su H, et al: Pacer is a mediator of mTORC1 and GSK3TIP60 signaling in regulation of autophagosome maturation and lipid metabolism. Mol Cell 73: 788-802.e7, 2019.

26. Eskelinen EL: Roles of LAMP-1 and LAMP-2 in lysosome biogenesis and autophagy. Mol Aspects Med 27: 495-502, 2006.

27. Zhang H: Targeting autophagy in lymphomas: A double-edged sword? Int J Hematol 107: 502-512, 2018.

28. Nagar R: Autophagy: A brief overview in perspective of dermatology. Indian J Dermatol Venereol Leprol 83: 290-297, 2017.

29. Rustin M: Postmodernism and antimodernism in contemporary British architecture. Assemblage 10: 89-103, 1989

30. Nakamura O, Hitora T, Yamagami Y, Mori M, Nishimura H, Horie $\mathrm{R}$, et al: The combination of rapamycin and MAPK inhibitors enhances the growth inhibitory effect on Nara-H cells. Int J Mol Med 33: 1491-1497, 2014.

31. Reddy D, Kumavath R, Tan TZ, Ampasala DR and Kumar AP: Peruvoside targets apoptosis and autophagy through MAPK $\mathrm{Wnt} / \beta$-catenin and PI3K/AKT/mTOR signaling pathways in human cancers. Life Sci 241: 117147, 2020.

32. Bhaskar PT and Hay N: The two TORCs and Akt. Dev Cell 12 487-502, 2007.

33. Loewith R, Jacinto E, Wullschleger S, Lorberg A, Crespo JL, Bonenfant D, Oppliger W, Jenoe P and Hall MN: Two TOR complexes, only one of which is rapamycin sensitive, have distinct roles in cell growth control. Mol Cell 10: 457-468, 2002.

34. Julien LA, Carriere A, Moreau J and Roux PP: mTORC1activated S6K1 phosphorylates Rictor on threonine 1135 and regulates mTORC2 signaling. Mol Cell Biol 30: 908-921, 2010.

35. Wang $\mathrm{Y}$ and Zhang H: Regulation of autophagy by mTOR signaling pathway. Adv Exp Med Biol 1206: 67-83, 2019.

36. Petherick KJ, Conway OJ, Mpamhanga C, Osborne SA, Kamal A, Saxty B and Ganley IG: Pharmacological inhibition of ULK1 kinase blocks mammalian target of rapamycin (mTOR)dependent autophagy. J Biol Chem 290: 11376-11383, 2015.

37. Joseph B, Kumar RV, Champaka G, Shenoy A, Sabitha KS, Lokesh V, Ramesh C and Vijay CR: Biological tailoring of adjuvant radiotherapy in head and neck and oral malignancies - The potential role of p53 and eIF4E as predictive parameters. Indian J Cancer 56: 330-334, 2019.

38. Huang CI, Wang CC, Tai TS, Hwang TZ, Yang CC, Hsu CM and Su YC: eIF4E and 4EBP1 are prognostic markers of head and neck squamous cell carcinoma recurrence after definitive surgery and adjuvant radiotherapy. PLoS One 14: e0225537, 2019.
39. Alabdullah ML, Ahmad DA, Moseley P, Madhusudan S, Chan S and Rakha E: The mTOR downstream regulator (p-4EBP1) is a novel independent prognostic marker in ovarian cancer. J Obstet Gynaecol 39: 522-528, 2019.

40. Gleason CE, Oses-Prieto JA, Li KH, Saha B, Situ G, Burlingame AL and Pearce D: Phosphorylation at distinct subcellular locations underlies specificity in mTORC2-mediated activation of SGK1 and Akt. J Cell Sci 132: 1-16, 2019.

41. Liu Y, Ao X, Ding W, Ponnusamy M, Wu W, Hao X, Yu W, Wang Y, Li P and Wang J: Critical role of FOXO3a in carcinogenesis. Mol Cancer 17: 104-115, 2018.

42. Ni HM, Du K, You M and Ding WX: Critical role of FoxO3a in alcohol-induced autophagy and hepatotoxicity. Am J Pathol 183: $1815-1825,2013$

43. Carnero A and Paramio JM: The PTEN/PI3K/AKT pathway in vivo, cancer mouse models. Front Oncol 4: 252, 2014.

44. Carnero A, Blanco-Aparicio C, Renner O, Link W and Leal JF: The PTEN/PI3K/AKT signalling pathway in cancer, therapeutic implications. Curr Cancer Drug Targets 8: 187-198, 2008.

45. Mangé A, Coyaud E, Desmetz C, Laurent E, Béganton B, Coopman P, Raught B and Solassol J: FKBP4 connects mTORC2 and PI3K to activate the PDK1/Akt-dependent cell proliferation signaling in breast cancer. Theranostics 9: 7003-7015, 2019.

46. Wang P, Gao W, Wang Y and Wang J: Acetylshikonin inhibits in vitro and in vivo tumorigenesis in cisplatin-resistant oral cancer cells by inducing autophagy, programmed cell death and targeting m-TOR/PI3K/Akt signalling pathway. J BUON 24: 2062-2067, 2019

47. Huang S, Xie T and Liu W: Icariin inhibits the growth of human cervical cancer cells by inducing apoptosis and autophagy by targeting mTOR/PI3K/AKT signalling pathway. J BUON 24: 990-996, 2019.

48. Agostini D, Natalucci V, Baldelli G, De Santi M, Donati Zeppa S, Vallorani L, Annibalini G, Lucertini F, Federici A, Izzo R, Stocchi V and Barbieri E: New insights into the role of exercise in inhibiting mTOR signaling in triple-negative breast cancer. Oxid Med Cell Longev 2018: 5896786, 2018. https://doi. org/10.1155/2018/5896786.

49. Han Y, Shi D and Li J: Inhibition of nasopharyngeal carcinoma by beta-lapachone occurs by targeting the mammalian target of rapamycin (mTOR)/PI3K/AKT pathway, reactive oxygen species (ROS) production, and autophagy induction. Med Sci Monit 25: 8995-9002, 2019.

50. Liu J, Ren Y, Hou Y, Zhang C, Wang B, Li X, Sun R and Liu J: Dihydroartemisinin induces endothelial cell autophagy through suppression of the Akt/mTOR pathway. J Cancer 10: 6057-6064, 2019.

51. Dong F, Han J, Jing G, Chen X, Yan S, Yue L, Cao Z, Liu X, Ma G and Liu J: Dihydroartemisinin transiently activates the JNK/SAPK signaling pathway in endothelial cells. Oncol Lett 12: 4699-4704, 2016

52. Li WD, Zhou DM, Sun LL, Xiao L, Liu Z, Zhou M, Wang WB and Li XQ: LncRNA WTAPP1 promotes migration and angiogenesis of endothelial progenitor cells via MMP1 through microRNA 3120 and Akt/PI3K/autophagy pathways. Stem Cells 36: 1863-1874, 2018.

53. Liu R, Chen Z, Yi X, Huang F, Hu G, Liu D, Li X, Zhou H and Liu Z: 9za plays cytotoxic and proapoptotic roles and induces cytoprotective autophagy through the PDK1/Akt/mTOR axis in non-small-cell lung cancer. J Cell Physiol 234: 20728-20741, 2019.

54. Dowling RJ, Topisirovic I, Fonseca BD and Sonenberg N: Dissecting the role of mTOR: Lessons from mTOR inhibitors. Biochim Biophys Acta 1804: 433-439, 2010.

55. Gera $\mathbf{J}$ and Lichtenstein A: The mammalian target of rapamycin pathway as a therapeutic target in multiple myeloma. Leuk Lymphoma 52: 1857-1866, 2011.

56. Engelman JA, Luo J and Cantley LC: The evolution of phosphatidylinositol 3-kinases as regulators of growth and metabolism. Nat Rev Genet 7: 606-619, 2006.

57. Tan FH, Bai Y, Saintigny P and Darido C: mTOR signalling in head and neck cancer: Heads Up. Cells 8: 333, 2019.

58. $\mathrm{Bu} \mathrm{Z}$ and Ji J: Therapeutic implications of mTOR inhibitors in the treatment of gastric cancer. Curr Cancer Drug Targets 13: 121-125, 2013.

59. Alvarez RH, Bechara RI, Naughton MJ, Adachi JA and Reuben JM: Emerging perspectives on MTOR inhibitor-associated pneumonitis in breast cancer. Oncologist 23: 660-669, 2018. 
60. Chang L, Graham PH, Ni J, Hao J, Bucci J, Cozzi PJ and Li Y: Targeting PI3K/Akt/mTOR signaling pathway in the treatment of prostate cancer radioresistance. Crit Rev Oncol Hematol 96: 507-517, 2015.

61. Myers AP: New strategies in endometrial cancer: Targeting the $\mathrm{PI} 3 \mathrm{~K} / \mathrm{mTOR}$ pathway--the devil is in the details. Clin Cancer Res 19: 5264-5274, 2013.

62. Wu CE, Chen $\mathrm{MH}$ and Yeh $\mathrm{CN}$ : mTOR inhibitors in advanced biliary tract cancers. Int J Mol Sci 20: 500, 2019. https://doi. org/10.3390/ijms20030500.

63. Ching CB and Hansel DE: Expanding therapeutic targets in bladder cancer: The PI3K/Akt/mTOR pathway. Lab Invest 90: 1406-1414, 2010

64. Rodrik-Outmezguine VS, Okaniwa M, Yao Z, Novotny CJ, McWhirter C, Banaji A, Won $\mathrm{H}$, Wong W, Berger $\mathrm{M}$, de Stanchina E, et al: Overcoming mTOR resistance mutations with a new-generation mTOR inhibitor. Nature 534: 272-276, 2016.

65. Yu C, Sun P, Zhou Y, Shen B, Zhou M, Wu L and Kong M: Inhibition of AKT enhances the anti-cancer effects of Artemisinin in clear cell renal cell carcinoma. Biomed Pharmacother 118: 109383, 2019.

66. Vinayak S and Carlson RW: mTOR inhibitors in the treatment of breast cancer. Oncology (Williston Park) 27: 38-44, 46, 48 passim, 2013

67. Martisova A, Sommerova L, Kuricova K, Podhorec J, Vojtesek B, Kankova K and Hrstka R: AGR2 silencing contributes to metformin-dependent sensitization of colorectal cancer cells to chemotherapy. Oncol Lett 18: 4964-4973, 2019.

68. Ciccarese F, Zulato E and Indraccolo S: LKB1/AMPK pathway and drug response in cancer: A therapeutic perspective. Oxid Med Cell Longev 2019: 8730816, 2019.

69. Richani D, Lavea CF, Kanakkaparambil R, Riepsamen AH, Bertoldo MJ, Bustamante S and Gilchrist RB: Participation of the adenosine salvage pathway and cyclic AMP modulation in oocyte energy metabolism. Sci Rep 9: 18395-18406, 2019.

70. Lu C, Wang W, Jia Y, Liu X, Tong Z and Li B: Inhibition of AMPK/autophagy potentiates parthenolide-induced apoptosis in human breast cancer cells. J Cell Biochem 115: 1458-1466, 2014

71. Chen W, Pan Y, Wang S, Liu Y, Chen G, Zhou L, Zhang C, Ni W, Wang A, Lu Y, et al: Correction to: cryptotanshinone activates AMPK-TSC2 axis leading to inhibition of mTORC1 signaling in cancer cells. BMC Cancer 19: 257-269, 2019.

72. Andrade BM and de Carvalho DP: Perspectives of the AMP-activated kinase (AMPK) signalling pathway in thyroid cancer. Biosci Rep 34: e00105, 2014.

73. Li F, Yang C, Zhang HB, Ma J, Jia J, Tang X, Zeng J, Chong T, Wang X, He D, et al: BET inhibitor JQ1 suppresses cell proliferation via inducing autophagy and activating LKB1/AMPK in bladder cancer cells. Cancer Med 8: 4792-4805, 2019.

74. Zhao Z, Feng L, Wang J, Cheng D, Liu M, Ling M, Xu W and Sun K: NPC-26 kills human colorectal cancer cells via activating AMPK signaling. Oncotarget 8: 18312-18321, 2017.

75. Chen L, Liu M, Luan Y, Liu Y, Zhang Z, Ma B, Liu X and Liu Y: BMP-6 protects retinal pigment epithelial cells from oxidative stress-induced injury by inhibiting the MAPK signaling pathways. Int J Mol Med 42: 1096-1105, 2018.

76. Ma Z, Wang C, Liu C, Yan DY, Tan X, Liu K, Jing MJ, Deng Y, Liu W and Xu B: Manganese induces autophagy dysregulation: The role of S-nitrosylation in regulating autophagy related proteins in vivo and in vitro. Sci Total Environ 698: 134294, 2020.

77. Pan MY, Shen YC, Lu CH, Yang SY, Ho TF, Peng YT and Chang CC: Prodigiosin activates endoplasmic reticulum stress cell death pathway in human breast carcinoma cell lines. Toxicol Appl Pharmacol 265: 325-334, 2012.

78. Kim JS, Bae GE, Kim KH, Lee SI, Chung C, Lee D, Lee TH, Kwon IS and Yeo MK: Prognostic significance of LC3B and p62/ SQSTM1 expression in gastric adenocarcinoma. Anticancer Res 39: 6711-6722, 2019

79. Zhang J, Yang S, Xu B, Wang T, Zheng Y, Liu F, Ren F, Jiang J, Shi H, Zou B, et al: p62 functions as an oncogene in colorecta cancer through inhibiting apoptosis and promoting cell proliferation by interacting with the vitamin D receptor. Cell Prolif 52: e12585, 2019.

80. Tan P, Ye Y, He L, Xie J, Jing J, Ma G, Pan H, Han L, Han W and Zhou Y: TRIM59 promotes breast cancer motility by suppressing p62-selective autophagic degradation of PDCD10. PLoS Biol 16: e3000051, 2018.
81. Schläfli AM, Adams O, Galván JA, Gugger M, Savic S, Bubendorf L, Schmid RA, Becker KF, Tschan MP, Langer R, et al: Prognostic value of the autophagy markers LC3 and p62/SQSTM1 in early-stage non-small cell lung cancer. Oncotarget 7: 39544-39555, 2016.

82. Chen Y, Zhou X, Qiao J and Bao A: Autophagy is a regulator of TRAIL-induced apoptosis in NSCLC A549 cells. J Cell Commun Signal 11: 219-226, 2017.

83. Wechman SL, Rao XM, Gomez-Gutierrez JG, Zhou HS and McMasters KM: The role of JNK phosphorylation as a molecular target to enhance adenovirus replication, oncolysis and cancer therapeutic efficacy. Cancer Biol Ther 19: 1174-1184, 2018.

84. Wang Y, Xiong H, Liu D, Hill C, Ertay A, Li J, Zou Y, Miller P, White E, Downward J, et al: Autophagy inhibition specifically promotes epithelial-mesenchymal transition and invasion in RAS-mutated cancer cells. Autophagy 15: 886-899, 2019.

85. Bryant KL, Stalnecker CA, Zeitouni D, Klomp JE, Peng S, Tikunov AP, Gunda V, Pierobon M, Waters AM, George SD, et al: Combination of ERK and autophagy inhibition as a treatment approach for pancreatic cancer. Nat Med 25: 628-640, 2019.

86. Mou L, Liang B, Liu G, Jiang J, Liu J, Zhou B, Huang J, Zang N, Liao Y, Ye L, et al: Berbamine exerts anticancer effects on human colon cancer cells via induction of autophagy and apoptosis, inhibition of cell migration and MEK/ERK signalling pathway. J BUON 24: 1870-1875, 2019.

87. Tian Y, Song W, Li D, Cai L and Zhao Y: Resveratrol as a Natural regulator of autophagy for prevention and treatment of cancer. OncoTargets Ther 12: 8601-8609, 2019.

88. Sánchez-Martín P, Saito T and Komatsu M: p62/SQSTM1: 'Jack of all trades' in health and cancer. FEBS J 286: 8-23, 2019.

89. Li Y, Shi J, Qi S, Zhang J, Peng D, Chen Z, Wang G, Wang Z and Wang L: IL-33 facilitates proliferation of colorectal cancer dependent on COX2/PGE2. J Exp Clin Cancer Res 37: 196-227, 2018.

90. Panigrahi DP, Bhol CS, R N, Nagini S, Patil S, Maiti TK and Bhutia SK: Abrus agglutinin inhibits oral carcinogenesis through inactivation of NRF2 signaling pathway. Int J Biol Macromol 9: 1-31, 2019.

91. Yang L, Sun X, Ye Y, Lu Y, Zuo J, Liu W, Elcock A and Zhu S: p38 a mitogen-activated protein kinase is a druggable target in pancreatic adenocarcinoma. Front Oncol 9: 1294-1314, 2019.

92. Patel PH, Pénalva C, Kardorff M, Roca M, Pavlović B, Thiel A, Teleman AA and Edgar BA: Damage sensing by a Nox-Ask1MKK3-p38 signaling pathway mediates regeneration in the adult Drosophila midgut. Nat Commun 10: 4365-4378, 2019.

93. Del Barco Barrantes I, Stephan-Otto Attolini C, Slobodnyuk K, Igea A, Gregorio S, Gawrzak S, Gomis RR and Nebreda AR: Regulation of mammary luminal cell fate and tumorigenesis by p38 $\alpha$. Stem Cell Reports 10: 257-271, 2018.

94. Mo'men YS, Hussein RM and Kandeil MA: A novel chemoprotective effect of tiopronin against diethylnitrosamine-induced hepatocellular carcinoma in rats: Role of ASK1/P38 MAPK-P53 signalling cascade. Clin Exp Pharmacol Physiol 47: 322-332, 2020 .

95. Aggarwal V, Tuli HS, Varol A, Thakral F, Yerer MB, Sak K, Varol M, Jain A, Khan MA and Sethi G: Role of reactive oxygen species in cancer progression: Molecular mechanisms and recent advancements. Biomolecules 9: 735-750, 2019.

96. Boldbaatar J, Gunarta IK, Suzuki R, Erdenebaatar P, Davaakhuu G, Hohjoh $\mathrm{H}$ and Yoshioka K: Protective role of c-Jun $\mathrm{NH}_{2}$-terminal kinase-associated leucine zipper protein (JLP) in curcumin-induced cancer cell death. Biochem Biophys Res Commun 29: 1-31, 2019.

97. Shi Y, Liu Y, Zheng Y, Tang Y, Zhu G, Qiu W, Huang L, Han S, Yin J, Peng B, et al: Autophagy triggered by MAVS inhibits Coxsackievirus A16 replication. Acta Virol 63: 392-402, 2019.

98. Yuan YL, Jiang N, Li ZY, Song ZZ, Yang ZH, Xue WH, Zhang XJ and Du Y: Polyphyllin VI induces apoptosis and autophagy in human osteosarcoma cells by modulation of ROS/JNK activation. Drug Des Devel Ther 13: 3091-3103, 2019.

99. Zhao M, Gu L, Li Y, Chen S, You J, Fan L, Wang Y and Zhao L: Chitooligosaccharides display anti-tumor effects against human cervical cancer cells via the apoptotic and autophagic pathways. Carbohydr Polym 224: 115171-115184, 2019.

100. Cheng X, Tan S, Duan F, Yuan Q, Li Q and Deng G: Icariin induces apoptosis by suppressing autophagy in tamoxifenresistant breast cancer cell line MCF-7/TAM. Breast Cancer 26: 766-775, 2019. 
101.Kim KY, Oh TW, Yang HJ, Kim YW, Ma JY and Park KI: Ethanol extract of Chrysanthemum zawadskii Herbich induces autophagy and apoptosis in mouse colon cancer cells through the regulation of reactive oxygen species. BMC Complement Altern Med 19: 274-283, 2019.

102. Wang F, Chen Y, Wang Y, Yin Y, Qu G, Song M and Wang H: Ultra-long silver nanowires induced mitotic abnormalities and cytokinetic failure in A549 cells. Nanotoxicology 13: 543-557, 2019

103. Chen G, Ding XF, Bouamar H, Pressley K and Sun LZ: Everolimus induces G1 cell cycle arrest through autophagymediated protein degradation of cyclin D1 in breast cancer cells Am J Physiol Cell Physiol 317: C244-C252, 2019.

104. Booth L, Roberts JL, Avogadri-Connors F, Cutler RE Jr, Lalani AS, Poklepovic A and Dent P: The irreversible ERBB1/2/4 inhibitor neratinib interacts with the BCL-2 inhibitor venetoclax to kill mammary cancer cells. Cancer Biol Ther 19: 239-247, 2018.

105.Zhou D, Dai L, Liu X, Que F, Xu Y, Luo X, Zhu Y, Liu S, Li Y and $\mathrm{Yu} \mathrm{L}$ : Bortezomib and obatoclax for dual blockade of protein degradation pathways show synergistic anti-tumor effect in human acute T lymphoblastic leukemia cells. Nan Fang Yi Ke Da Xue Xue Bao 39: 401-408, 2019 (In Chinese).

106. Antonietti P, Gessler F, Düssmann H, Reimertz C, Mittelbronn M, Prehn JH and Kögel D: AT-101 simultaneously triggers apoptosis and a cytoprotective type of autophagy irrespective of expression levels and the subcellular localization of Bcl-xL and Bcl-2 in MCF7 cells. Biochim Biophys Acta 1863: 499-509, 2016

107. Tong H, Li T, Qiu W and Zhu Z: Claudin-1 silencing increases sensitivity of liver cancer HepG2 cells to 5 -fluorouracil by inhibiting autophagy. Oncol Lett 18: 5709-5716, 2019.

108. Lee J, Jung JH, Hwang J, Park JE, Kim JH, Park WY, Suh JY and Kim SH: CNOT2 is critically involved in atorvastatin induced apoptotic and autophagic cell death in non-small cell lung cancers. Cancers (Basel) 11: 1470-1484, 2019.

109. Lee JE, Yoon SS and Moon EY: Curcumin-induced autophagy augments its antitumor effect against A172 human glioblastoma cells. Biomol Ther (Seoul) 27: 484-491, 2019.

110. Silva VAO, Rosa MN, Tansini A, Martinho O, Tanuri A Evangelista AF, Cruvinel Carloni A, Lima JP, Pianowski LF and Reis RM: Semi-synthetic ingenol derivative from euphorbia tirucalli inhibits protein kinase $\mathrm{C}$ isotypes and promotes autophagy and S-phase arrest on glioma cell lines. Molecules 24: 4265-4282, 2019.

111. Robke L, Laraia L, Carnero Corrales MA, Konstantinidis G, Muroi M, Richters A, Winzker M, Engbring T, Tomassi S Watanabe N, et al: Phenotypic identification of a novel autophagy inhibitor chemotype targeting lipid kinase VPS34. Angew Chem Int Ed Engl 56: 8153-8157, 2017.
112. Carew JS, Espitia CM, Zhao W, Han Y, Visconte V, Phillips J and Nawrocki ST: Disruption of autophagic degradation with ROC-325 antagonizes renal cell carcinoma pathogenesis. Clin Cancer Res 23: 2869-2879, 2017.

113. Guntuku L, Gangasani JK, Thummuri D, Borkar RM, Manavathi B, Ragampeta S, Vaidya JR, Sistla R and Vegi NGM: IITZ-01, a novel potent lysosomotropic autophagy inhibitor, has single-agent antitumor efficacy in triple-negative breast cancer in vitro and in vivo. Oncogene 38: 581-595, 2018.

114. Wu MY, Wang SF, Cai CZ, Tan JQ, Li M, Lu JJ, Chen XP, Wang YT, Zheng W and Lu JH: Natural autophagy blockers, dauricine (DAC) and daurisoline (DAS), sensitize cancer cells to camptothecin-induced toxicity. Oncotarget 8: 77673-77684, 2017.

115. Zhao Y, Li K, Zhao B, Su L, Li K, Zhao B and Su L: HSP90 inhibitor DPB induces autophagy and more effectively apoptosis in A549 cells combined with autophagy inhibitors. In Vitro Cell Dev Biol Anim 55: 349-354, 2019.

116. Han J, Lv W, Sheng H, Wang Y, Cao L, Huang S, Zhu L and $\mathrm{Hu} \mathrm{J}$ : Ecliptasaponin A induces apoptosis through the activation of ASK1/JNK pathway and autophagy in human lung cancer cells. Ann Transl Med 7: 539-560, 2019.

117. Polishchuk EV, Merolla A, Lichtmannegger J, Romano A, Indrieri A, Ilyechova EY, Concilli M, De Cegli R, Crispino R, Mariniello M, et al: Activation of autophagy, observed in liver tissues from patients with Wilson disease and from ATP7Bdeficient animals, protects hepatocytes from copper-induced apoptosis. Gastroenterology 156: 1173-1189.e5, 2019.

118. Klionsky DJ, Abdelmohsen K, Abe A, Abedin MJ, Abeliovich H, Acevedo Arozena A, Adachi H, Adams CM, Adams PD, Adeli $\mathrm{K}$, et al: Guidelines for the use and interpretation of assays for monitoring autophagy (3rd edition). Autophagy 12: 1-222, 2016.

119. Xuan F, Huang M, Liu W, Ding H, Yang L and Cui H: Homeobox C9 suppresses Beclin1-mediated autophagy in glioblastoma by directly inhibiting the transcription of deathassociated protein kinase 1. Neuro-oncol 18: 819-829, 2016.

120.Du H, Che J, Shi M, Zhu L, Hang JB, Chen Z and Li H Beclin 1 expression is associated with the occurrence and development of esophageal squamous cell carcinoma. Oncol Lett 14: 6823-6828, 2017.

121. Chu C, Niu X, Ou X and Hu C: LAPTM4B knockdown increases the radiosensitivity of EGFR-overexpressing radioresistant nasopharyngeal cancer cells by inhibiting autophagy. OncoTargets Ther 12: 5661-5677, 2019.

This work is licensed under a Creative Commons Attribution-NonCommercial-NoDerivatives 4.0 International (CC BY-NC-ND 4.0) License. 